(RESUMO DOS TRABALHOS PREMIADOS: PESQUISA DE ALUNOS DE GRADUAÇÃO)

\title{
A TEMÁTICA ADMINISTRAÇÃO DE MEDICAMENTOS NAS PESQUISAS EM ENFERMAGEM
}

Adriane Paravella de Fátima*

A administração de medicamentos é função da enfermagem. as questões norteadoras deste estudo foram: como a enfermagem tem trazido à baila da pesquisa o tema administração de medicamentos? A questão técnica é a que prevalece? O que as revistas têm publicado sobre o tema? Identificamos doze artigos, sendo cinco publicados na década de 70 e o restante na década de 80. Os artigos foram agrupados em quatro tipos: Estudos que tratam dos princípios científicos na administração de medicamentos, estudos que tratam das regiões e as técnicas de aplicação de injeção por via I. M., estudos que identificam o rendimento instrumental da ministração de medicamentos e estudos que apresentam uma preocupação com a participação e a reação da clientela a ministração de medicamentos. Nossos dados apresentaram que estudos que trataram basicamente sobre a técnica, o instrumental e o rendimento dos aplicadores foram divulgados na década de 70 enquanto que a década de 80 caracterizou-se por estudos que tratavam sobre os princípios científicos e de preocupações humanistas denotadas pela observação sobre a reação e participação da clientela no processo.

* Aluna do $8^{\circ}$ Semestre do Curso de graduação da Escola de Enfermagem de Ribeirão Preto da Universidade de São Paulo 